\title{
Patient-Reported Outcome Measures (PROMs) to Support Adherence to Falls Prevention Clinic Recommendations: A Qualitative Study
}

This article was published in the following Dove Press journal: Patient Preference and Adherence

\author{
Daria Tai ${ }^{1-4}$ \\ Eric $\mathrm{Li}^{1}$
}

Teresa Liu-Ambrose ${ }^{2-4}$

Nick Bansback ${ }^{5,6}$

Mohsen Sadatsafavi $\mathbb{D}^{7,8}$

Jennifer C Davis ${ }^{1-3}$

'Social \& Economic Change Laboratory, Faculty of Management, University of British Columbia - Okanagan, Kelowna, British Columbia, Canada; ${ }^{2}$ Center for Hip Health and Mobility, Vancouver Coastal Health Research Institute, University of British Columbia, Vancouver, British Columbia, Canada;

${ }^{3}$ Aging, Mobility, and Cognitive Neuroscience Lab, Department of Physical Therapy, Faculty of Medicine, University of British Columbia,

Vancouver, British Columbia, Canada;

${ }^{4}$ Djavad Mowafaghian Centre for Brain Health, University of British Columbia, Vancouver, British Columbia, Canada;

${ }^{5}$ School of Population and Public Health, University of British Columbia -

Vancouver, Vancouver, British Columbia, Canada; ${ }^{6}$ Centre for Health Evaluation \& Outcome Sciences, University of British Columbia, Vancouver, British Columbia, Canada; ${ }^{7}$ Faculty of Pharmaceutical Sciences, University of British Columbia Vancouver, Vancouver, British Columbia, Canada; ${ }^{8}$ Collaboration for Outcomes Research and Evaluation, University of British Columbia, Vancouver, British Columbia, Canada

Correspondence: Jennifer C Davis Faculty of Management, The University of British Columbia - Okanagan, II 37 Alumni Avenue, Kelowna, BC VIV IV7, Canada

Tel +I 2508079507

Email jennifer.davis@ubc.ca
Purpose: We examined how patient-reported outcome measures (PROMs) support patients' adherence to fall prevention recommendations in a novel primary care setting - the Falls Prevention Clinic.

Patients and Methods: Using a patient-oriented qualitative study design, we recruited patient partners to our study team to assist in developing focus group prompts. A trained facilitator conducted five semi-structured interviews with a total of 21 Falls Prevention Clinic participants. A trained facilitator prompted participants about: their views on the EuroQol 5 domain - 5 level (EQ-5D-5L) PROM, their preferences for PROM administration and feedback, the presentation of PROM questionnaire data, the use of comparative data and the EQ-5D-5L in improving adherence to recommendations, and other information they would need to improve adherence. Participants' responses were coded according to three stages of qualitative analysis: open, axial and selective coding using an iterative and comparative approach.

Results: "Opportunity" and "Development" emerged as higher-level themes for the participants' perspectives on how the EQ-5D-5L may be helpful for their appointments. "Frequency" described how often the participants believed the EQ-5D-5L should be administered and feedback provided. "Challenges", "Benefits", "Patients' Understanding”, "Relevance of Data", and "Usefulness of Data" provided insight on how PROMs data presentation was viewed by patients. "Performance", "Resources", "Knowledge", "Role in Behaviour Change" highlighted the participants' ideas for the role of the EQ-5D-5L and additional information in supporting their adherence to falls prevention recommendations. Participants emphasized that patients would value further support information to facilitate their adherence.

Conclusion: This patient-oriented qualitative study, among individuals at high risk of future falls, sheds light on the importance of timely, understandable feedback, integrated with other clinical feedback in supporting adherence.

Keywords: EQ-5D-5L, patient-physician communication, administration, self-awareness, adherence, falls

\section{Introduction}

Falls are a common geriatric syndrome and a leading cause of chronic disability from injury and mortality worldwide. ${ }^{1-3}$ Of the $30 \%$ of community-dwelling seniors who fall, half fall recurrently and are at significant risk for hospitalization, institutionalization, and death. ${ }^{4-6}$ As the proportion of the population over 65 continues to increase, falls will place an increasing demand and cost on the public health system. ${ }^{7}$ 
Falls are preventable using a multifactorial prevention approach in a falls prevention clinical setting ${ }^{8}$ that targets multiple risk factors for falling based on an individual's fall risk profile. Meta-analytic ${ }^{9}$ and systematic review data demonstrate that a multifactorial fall risk assessment and management program can reduce falls; this effect was stronger for individuals at higher risk for falls. ${ }^{10}$ Such a clinical setting was evaluated in the seminal Prevention Of Falls in the Elderly Trial (PROFET) study; ${ }^{11}$ this multifactorial individually tailored intervention led by a geriatrician reduced falls by approximately $30 \%{ }^{11}$ Falls Prevention Clinics that have demonstrated feasibility and success in falls prevention include the Finish Falls Prevention Clinic and the Vancouver Falls Prevention Clinic. ${ }^{8,12}$ The Finnish Falls Prevention Clinic randomized controlled trial demonstrated a $26 \%$ reduction in falls and fall-related injuries among patients attending a multifactorial individually tailored Falls Prevention Clinic. ${ }^{8}$ A Falls Prevention Clinic provides a feasible way to deliver multifactorial falls prevention to high-risk patients in a medical clinic setting dedicated to falls prevention. 8,12

The degree of effectiveness of a physician-led multidisciplinary falls prevention program may be limited by adherence to recommendations. ${ }^{13}$ Despite established efficacy for fall prevention interventions in reducing falls, adherence to lifestyle or exercise interventions is generally lower compared with adherence to medication changes and physician referrals. ${ }^{12,14,15}$ We postulate that lower adherence may diminish some intervention benefits. Many studies report a $50 \%$ adherence rate or lower. ${ }^{16-18}$ A critical void exists in our understanding of the patient's perspective and role in assessing their own health and how or if it contributes to adherence.

Patient-reported outcome measures (PROMs) are selfassessments of various aspects of patients' health status; historically, these are measured for research purposes. ${ }^{19}$ For example, PROMs data are often used as outcome measures in clinical trials and to identify important clinical drivers of health-related quality of life and health resource use, as well as quantitative descriptions of patient adherence and overall patient experience. ${ }^{20-22}$ More broadly, PROMs are increasingly recognized for their role in primary care clinical settings. ${ }^{19,23-27}$ For example, PROMs data were used to customize patient education and provide feedback for the physician. It improved medical care, resulted in greater assistance with functional or clinical problems for older patients and provided better patient understanding of threats to their health. ${ }^{28}$ PROMs may positively impact clinical management through shared practitioner/patient decision-making, ${ }^{29}$ the effectiveness depends on the quality of patient-physician communication. ${ }^{28,30,31}$ Additionally, PROMs may be used as a simple screening tool in primary care settings. $^{24,32}$ There remains limited research on how PROMs can be used in the clinical management of a Falls Prevention Clinic.

PROMs have demonstrated feasibility in a number of settings. Frequent collection (i.e., every 3 months) intervals are associated with higher response rates. ${ }^{33-35}$ Yet, PROMs are historically often implemented without input from patients. ${ }^{36}$ Patients are less likely to complete PROMs if they do not perceive or understand the value. ${ }^{23}$ A patient-oriented approach may be useful for improving PROMs completion rates, by promoting communication between the provider and the patient to gain patient input and to facilitate the patient's understanding of the PROM. Indeed, when PROMs completion is synchronous with a patient's clinic appointment, completion rates are higher. ${ }^{37}$

Patient benefits received from an intervention can be limited by failure to fully or partially adhere to recommendations. ${ }^{38}$ Patients' motivation to adhere to recommendations is partly influenced by pre-existing attitudes, beliefs, and expectations toward their condition and treatment. ${ }^{39-42}$ Clear information about regimens is often not enough to ensure adherence, ${ }^{43}$ highlighting the strong influence of patients' intrinsic beliefs about their condition and treatment. ${ }^{44-46}$ Patients' intrinsic beliefs include their own understanding and perception of how the regimen will affect their condition, and whether it makes sense to them. ${ }^{40}$ Patients who evaluate that their personal needs do not exceed their concerns about negative effects of treatments, such as viewing the treatment as unnecessary or unsafe may explain why they fail to adhere. ${ }^{42,47,48}$

The provider-patient relationship affects adherence by providing opportunities to address patients' concerns. ${ }^{42}$ Patient-physician communication is a significant predictor of treatment adherence because it facilitates patient involvement in decision-making. ${ }^{49-54}$ Building trust through tailored communication is also important for adherence to recommendations in a falls prevention clinic setting. ${ }^{55}$ Because PROMs influence shared decision-making, it is essential to explore the role of PROMs in supporting adherence. PROMs can encapsulate the personal impact 
of conditions and provide an objective measure that can be used during discussions to set expectations. ${ }^{24,40}$

In light of the potential benefits and feasibility of PROMs in primary care, we underscore the need to better understand the value of PROMs data in a Falls Prevention Clinic. The literature is devoid of how PROMS data may be used to support patients' decision-making regarding adherence to the falls prevention recommendations presented from a Falls Prevention Clinic. The effectiveness of using PROMs as a mechanism to promote patient adherence is also unknown. Hence, this study used a patient-oriented research approach by engaging patients as research partners to understand if PROMs data may improve patient adherence to falls prevention recommendations. The goal of improving patient's adherence to falls prevention recommendations is to reduce the number and rate of falls experienced by at-risk seniors. We used a context of patients at high risk of falls that present to a Falls Prevention Clinic for a fall in the previous 12 months to investigate these methods. Our primary objective was to explore Falls Prevention Clinic participants' perspectives on PROMs and on how PROMs might impact their own adherence to recommendations using a patientoriented qualitative study design with patient partners in British Columbia, Canada.

\section{Patients and Methods Setting}

This study took place at the Vancouver Falls Prevention Clinic where patients receive a comprehensive medical examination to identify their individual risk factors for falls and fall-related injuries at baseline with optional follow-ups at 6 and 12 months. A geriatrician assistant completes questionnaires and various functional, mobility, balance, strength and cognitive assessments. A geriatrician performs a comprehensive 1-hour medical checkup where the following factors were also reviewed: comprehensive medical exam, physical function, functional ability, physical activity or exercise (i.e., strength and balance retraining), nutrition, medication review, alcohol/smoking review and a home hazard assessment (via checklist). The best practices offered by the Falls Prevention Clinic follow an effective multifactorial approach. ${ }^{8}$ During their appointment, patients complete a PROM (EQ-5D-5L) questionnaire prior to receiving any clinical interventions, and repeat the PROMs questionnaire at six and/or 12 months post-baseline assessment if the patient is requested by the geriatrician to come back to the Falls Prevention Clinic at 6 and/or 12 months with a response rate of $99 \% .^{20}$ The EQ-5D-5L was selected for this study because it has demonstrated validity among individuals at risk of falling, ${ }^{56}$ it has demonstrated feasibility in a comparable population $^{12}$ and there is growing interest in its routine collection in primary care settings. 57

\section{Patient Partnership}

We recruited four (three active at a time) patient partners who attended the Falls Prevention Clinic previously to join our research team. Patient partners contributed to the research project, the study design and methodology section, as investigators with lived experience as patients of the Falls Prevention Clinic. Participants contributed to data collection. Due to the dynamic nature of our older patient partners' health status, we actively recruited new patient partners on an ongoing basis. Recruitment of new patient partners was based on retention of existing patient partners. If a patient partner became unable to participate due to health conditions, we actively recruited a new patient partner. Newly recruited patient partners were introduced to the study in full and provided with all the information the existing patient partners received. All patient partners were engaged throughout the research process including grant preparation, participant recruitment, focus group question design, refinement and feedback.

\section{Study Sample}

Eligible participants were those who met the inclusion criteria to attend the Falls Prevention Clinic. Participants were included if they were: 1) aged $\geq 70$ years referred by a medical professional to the Falls Prevention Clinic as a result of seeking medical attention for a non-syncopal low trauma fall in the previous 12 months. Falls were defined as

Unintentionally coming to the ground or some lower level and other than as a consequence of sustaining a violent blow, loss of consciousness, sudden onset of paralysis as in stroke or an epileptic seizure, ${ }^{58}$

2) able to understand, speak, and read English proficiently; 3) had an $\mathrm{MMSE}^{59}$ score $\geq 24 / 30$; 4) had a Physiological Profile Assessment (PPA)C) ${ }^{60}$ score of at least 1.0 SD above age-normative value or a Timed Up and Go Test (TUG) ${ }^{61}$ performance of greater than 15 seconds or one additional non-syncopal fall in the previous 12 months; 5) expected to live greater than 12 months (based on the geriatricians' expert opinion); 6) living in 
the Greater Vancouver area; 7) community-dwelling (i.e., not residing in a nursing home, extended care unit, or assisted-care facility); 8) able to walk 3 meters with or without an assistive device; and 9) able to provide written informed consent. Participants were excluded if they: 1) were previously diagnosed with or suspected (by the geriatrician) to have neurodegenerative disease (e.g., Parkinson's disease); 2) were previously diagnosed with or suspected (by the geriatrician) to have dementia (of any type); 3) had a stroke; or 4) had a history indicative of carotid sinus sensitivity (i.e., syncopal falls).

All participants signed written and informed consent to participate in this study and included publication of anonymised quotes, and this study was conducted in accordance with the Declaration of Helsinki. Ethical approval was obtained from the Vancouver Coastal Health Research Institute (V19-03192, November 27, 2019) and the University of British Columbia's Clinical Research Ethics Board (H19-03192, November 27, 2019).

\section{Study Design and Methodology}

Descriptive characteristics were collected for the following measures at baseline: age, sex, height, weight, education, instrumental activities of daily living, falls risk, balance and mobility, depression status and cognitive status. The Lawton and Brody Instrumental Activities of Daily Living Scale (IADL) assessed independent living skills (range 0-8, $8=$ best). ${ }^{62}$ The Physiological Profile Assessment (PPA) reports z-scores. A PPA z-score of 0-1 indicates mild risk for falling, 1-2 indicates moderate risk for falling, 2-3 indicates high risk for falling, and 3 and above indicates marked risk for falling. ${ }^{60}$ Balance and mobility were ascertained using the Short Physical Performance Battery (SPPB) (range $0-12,12=$ best; $\mathrm{MCID}=1.0$; scores $\leq 9 / 12$ predict subsequent disability). ${ }^{63}$ The 15 -item Geriatric Depression Scale (GDS) assessed mood (range 0-15, 0=best; scores $\leq 5$ are normal). ${ }^{64,65}$ Global cognitive function was measured with the Mini-Mental State Examination (MMSE) ${ }^{66}$ and the Montreal Cognitive Assessment (MoCA) ${ }^{67}$ (range 0-30 points for each measure, higher=better). MMSE scores $\geq$ 24/30 and MoCA scores $\geq 26 / 30$ indicate normal cognition.

To ensure we obtained a diverse array of perspectives and experiences, we purposively sampled participants on age, mobility and cognitive status within the limits of the inclusion and exclusion criteria. We recruited 21 participants with a range of demographic profiles from the Falls Prevention Clinic and conducted semi-structured interviews in order to understand patients' perspectives on how PROMs data could be used to inform them about the consequences of adherence to Falls Prevention Clinic recommendations. Each of the five focus groups conducted included a range of 4-6 participants. Focus group methodology was used for this study because we are at the initial stages of understanding the value and utility of PROMs in a Falls Prevention Clinic setting. ${ }^{68}$ Hence, focus groups are deemed beneficial for exploratory research. Focus group methods encouraged open communication among participants. As such, the power of a group dynamic to facilitate conversation and discovery about new topics in this setting was deemed particularly useful. Guided by our patient partners, we developed six open-ended questions in each interview, designed to elicit responses about patient adherence to recommendations, benefits from using PROMs data to inform their decisions to adhere, and potential areas for improvement within the clinic. The patient partners each met individually with our study team to provide feedback on the focus questions in advance of conducting the focus groups with participants. The patient partners were asked to provide their input based on the following prompts: 1) "Is there anything that could be a cause for confusion?" and 2) "What can be made more clear?" In summary, they suggested alternate and additional explanations of the questionnaire and proposed graphs for simplification. Following the input of our three patient partners, Table 1 describes the six questions included in the focus groups.

The same trained facilitator administered these questions to all focus group participants. Participants were made aware that the purpose of the interview was to better understand their perspectives on the use of PROMs data to promote their own adherence and were shown the EQ-5D-5L and respective graphs when they answered the questions. Patient partners were present for all focus groups and contributed to the focus groups by further simplifying any explanations that were still confusing for participants. After each focus group, the patient partners discussed what they thought were the main highlights with the facilitator separately.

\section{Data Analysis}

All analyses were conducted after data collection was completed. We coded the participant responses according to the three stages of qualitative analysis outlined by Strauss and Corbin: open coding, axial coding and selective coding. ${ }^{69}$ Briefly, in the initial data reduction stage, two readers (DT and JCD) repeatedly read participant responses from the interviews to highlight sections of data that informed the 
Table I Focus Group Prompts

I. Why do you think we ask you to complete this questionnaire? How do you think this measure (the EQ-5D-5L) might be helpful?

2. What are your feelings about the timing of feedback? How helpful would it be if administration of the EQ-5D-5L increased in frequency?

3. Do you think this type of information for tracking your health status over time is useful? What do you think might happen if you do not adhere? What do you think happens if you do adhere?

4. Would you like to be provided with comparative information of how you are doing relative to how the average population seen at the Falls Prevention Clinic is doing? Why or why not?

5. What type of information would you need to promote your adherence to Falls Prevention Clinic recommendations?

6. Where do you think the EQ-5D-5L could fit in to promoting your adherence?

research question (open coding). The first step in open coding was to ascribe individual codes representing main concepts to each line of the transcript. We then clustered ideas together to form emergent themes (axial coding) by two readers (DT and JCD). We highlight that this stage was an iterative process. Axial coding was characterized by sorting and condensing codes; we grouped similar concepts together. We explored relationships between codes. We completed the conclusion drawing and verification stage (selective coding) and established a finalized set of overarching themes. From our selective coding, we generated a final list of higher-level themes and associated categories that captured the main ideas provided by the focus group participants. The sample size of the study was based on the saturation of data. In this study, we defined saturation as the point where no new additional emergent themes were identified.

\section{Results}

A total of four patient partners ( 3 active at a time) were recruited. Of these, one patient partner withdrew from our study team due to a chronic condition. Upon their withdrawal, our study team actively recruited an additional patient partner.

We conducted 5 focus groups with a total of 21 participants, who had an average age of 82 (8) years. Table 2 provides demographic characteristics of the participants included in the focus groups based on their profile at their initial appointment at the Falls Prevention Clinic. Participants in this sample are representative of the average population seen at the Vancouver Falls Prevention Clinic in terms of age, sex, mobility and cognitive status. Participants' average PPA score was 1.3 (SD: 1.1), their average MoCA score was 26.5 (SD: 2.2) and their average SPPB score was 9.9 (SD: 1.5).

The focus group questions were designed to elicit responses about six different yet connected topics. Table 3 summarizes the six key themes that emerged, and Table 4 provides quotes supporting each theme.

\section{Theme I: Usefulness of a Patient-Reported Outcome Measure (EQ-5D-5L) to Patients}

Focus group participants reported their assumptions for the purpose of PROMs completion and identified that it can be an opportunity at two distinct levels: 1) an opportunity for physicians to gain a patient's perspective about their condition and how it impacts their daily living and 2) an opportunity for comparison to delineate individualized trends of patients' wellbeing before and after going into the clinic. A participant stated: "I think if you came in here for the first time, you'd want to know something about us and how we feel about our condition." Another elaborated:

Table 2 Baseline Demographics $(n=2 I)$

\begin{tabular}{|c|c|c|}
\hline Variables & $\begin{array}{l}\text { Mean (SD) or } \\
\text { Frequency (\%) }\end{array}$ & $\begin{array}{l}\text { Range } \\
\text { (Min, } \\
\text { Max) }\end{array}$ \\
\hline Age & $8 I .1$ (6.5) & 66,93 \\
\hline $\begin{array}{l}\text { Sex } \\
\qquad \text { Male } \\
\text { Female }\end{array}$ & $\begin{array}{l}5(24.8) \\
16(76.2)\end{array}$ & N/A \\
\hline $\begin{array}{l}\text { Height }(\mathrm{cm}) \\
\text { Weight }(\mathrm{kg})\end{array}$ & $\begin{array}{l}161.1(8.5) \\
72.7(15.3)\end{array}$ & $\begin{array}{l}\mid 46.1,181.6 \\
48.5,109.1\end{array}$ \\
\hline $\begin{array}{l}\text { Education }(n=20) \\
\text { High school certificate or } \\
\text { diploma } \\
\text { Trades or professional } \\
\text { certificate or diploma } \\
\text { Some university certificate } \\
\text { or diploma } \\
\text { University degree }\end{array}$ & $\begin{array}{l}2(10) \\
7(35) \\
3(15) \\
8(40)\end{array}$ & N/A \\
\hline $\begin{array}{l}\text { IADL }(n=20) \\
\text { SPPB ( } 12 \text { points max }) \\
\text { PPA ( }-2 \text { to } 3)^{*} \\
\text { GDS ( } 30 \text { points max) } \\
\text { MMSE ( } 30 \text { points max) } \\
\text { MoCA ( } 30 \text { points max) } \\
\text { EQ-5L-5D score }(n=18)\end{array}$ & $\begin{array}{l}8.0(0.2) \\
9.8(1.6) \\
1.2(1.1) \\
1.7(2.1) \\
28.9(1.2) \\
26.6(2.3) \\
0.8(0.3)\end{array}$ & $\begin{array}{l}7,8 \\
7,12 \\
-0.3,3.4 \\
0,7 \\
26,30 \\
22,30 \\
0.1,1.0\end{array}$ \\
\hline
\end{tabular}

Note: ${ }^{*}$ A score of 3 indicates marked risk. 
Table 3 General Themes from Focus Groups Regarding the Role of PROMs (i.e., EQ-5D-5L) to Promote Adherence to Falls Prevention Clinic Recommendations

\begin{tabular}{|l}
\hline Theme I: Usefulness of a patient-reported outcome \\
measure (EQ-5D-5L) to patients \\
\hline Opportunity \\
Gaining the patient perspective \\
How patients are feeling \\
How patients' conditions affect their daily living \\
Gaining self-awareness \\
Brining issues to the patient's attention \\
For comparison \\
Follow up purposes \\
Possible trends \\
Development \\
Care pathway \\
Role in provider's/physician's decision of treatment plan \\
\hline Theme 2: EQ-5D-5L administration and feedback timing \\
\hline Frequency \\
When to receive feedback \\
Real-time \\
Patient's preference \\
Administration of questionnaire \\
Often is more helpful
\end{tabular}

Theme 3: Tracking health status over time - the relationship to adherence

\section{Benefits}

Comparison

Able to see if there are changes throughout time

To understand the treatment process

Motivation

Able to see improvements or declines

Challenges

Data presentation

Cause for confusion

Target audience

Patient vs Provider vs Research

Patients' understanding

Interpretation of the graphical data

Reasons for decline/incline

Theme 4: Comparison of PROM data with peers

Relevance of data

Relevance to self

Performance of others not relevant

Evidence for benefits from recommendations

Already knowing their own level of adherence

Need to be similar in demographics/conditions

Usefulness of data

For Patient

For motivation

(Continued)
Table 3 (Continued).

\begin{tabular}{|l|}
\hline For self-awareness \\
Figure out why they are in a certain group \\
For Provider \\
Find and provide reason for different levels of compliance \\
\hline Theme 5: Patient perspectives on promoting their own \\
adherence \\
\hline Performance \\
Direct feedback from the provider \\
Report of/asking how compliant they were \\
Resources \\
Lists \\
Recreation/exercise programs \\
Directly from provider \\
Ask what patients need \\
Knowledge \\
Effect of comorbidities \\
How it can hinder compliance \\
Self-reflection \\
Prompts to think about reasons they have not been complying \\
Theme 6: Potential role for the EQ-5D-5L in promoting \\
Already knowing own state of wellbeing \\
More important for provider \\
Positive reinforcement \\
Role in behaviour change \\
Not having a role \\
Rere
\end{tabular}

For me [the EQ-5D-5L] sort of covers how you're able to function. And you know, for that, I think it's a nice encapsulation ... whatever your condition, health condition, how you're managing in your life ... that's an indication of whether your condition, your health is interfering with your abilities to function in the world.

Those who talked about comparison purposes had similar thoughts: "... You get a sense of the progress or the fluctuations of your healing process." Participants also reported an opportunity for patients to gain more selfawareness of how their conditions affect their lives. Some participants pointed out: "There might be, some of these issues here, some of these items, that you really haven't thought about in a while." A minority of participants talked about it being more useful for the provider. They reported that the completion of a PROMs questionnaire may assist in the development of the primary care pathway for falls prevention: 
Table 4 Illustrative Quotes for Key Themes About the Role of PROMs (i.e., EQ-5D-5L) in Promoting Adherence to Falls Prevention Clinic Recommendations

THEME I: Usefulness of a patient-reported outcome measure (EQ-5D-5L) to patients

Higher Level Theme I: Opportunity

Predominant theme:

I. Gaining the patient's perspective

2. Gaining self-awareness

3. For comparison
Sub theme and quotes:

How patients are feeling

"I think if you came in here for the first time, you'd want to know something about us and how we feel about our condition."

How patients' conditions affect their daily living

"For me [the questionnaire] sort of covers how you're able to function. And you know, for that, I think it's a nice encapsulation ... whatever your condition, health condition, how you're managing in your life ... that's an indication of whether your condition, your health is interfering with your abilities to function in the world."

\section{Bringing issues to the patient's attention}

"There might be, some of these issues here, some of these items, that you really haven't thought about in a while." "... that it's something you might not have thought about for a while, and [think], "Oh gee, I guess that is true, so maybe I should follow-up and see my GP, because I am having more pain," something like that. It might make you think about something you had not thought about."

"I think it's helpful because it just makes us more self-aware, you know, I think that being self-aware when you're older it's very important because I live with somebody who has dementia and he's not self-aware. And so there's huge difference between my awareness of what's going on and everything in his. So, yes, I think it's important from that point of view."

\section{Follow up purposes}

"Think the idea of having it filled out again later, as a follow-up could really be an indication of whether there's been a change and whether the Falls Prevention Clinic had a role in it."

Possible trends

"[The provider] can compare to what we wrote when we first came to the Falls Prevention Clinic."

"We understand it could be different tomorrow or yesterday and that we'll be doing this each time you're

here ... So you get a sense of the progress or the fluctuations of your healing process ... Then I think it could be very interesting."

"I think it encourages us [to] see what's happening, [whether] we're improving or slipping and [if so,] it might just give us a little kick in the back in the bottom."

Higher Level Theme 2: Development

4. Care pathway

Role in provider's/physician's decision of treatment plan

"The patient might think that she's having acertain problem, and it turned out it's not that. And the doctor can redirect her to the correct treatment."

"[Providers should make recommendations] on the basis ... of what [they've] observed in the tests that are done and also in terms of the individual's approach to what the patient thinks."

\section{THEME 2: EQ-5D administration and feedback timing}

\section{Higher Level Theme 3: Frequency}

5. When to receive feedback

\section{Real-time}

"I just found that [it is] helpful is to have the person tell me how I respond to them on that particular day."

"We're here personally to understand our bodies and maybe learn something and maybe together not have so many falls, but that doesn't mean that the information we provide to the research team ... isn't important. It is very important. But for me personally ... you got to take it and run with it."

"I found it more helpful immediately when I was finished, and had an interview with the doctor, and I enjoyed that." Patient's preferences

"It would depend on each [person] ... whether they feel that they need [to]."

(Continued) 
Table 4 (Continued).

\begin{tabular}{|l|l}
\hline 6. Administration of questionnaire & $\begin{array}{l}\text { Often is more helpful } \\
\text { "I think it should be done that probably at least every three, if not two. And the reason I suggest that is } \\
\text { because I think there may be ... seasonal aspects to us. You may find you're doing more in the summer." } \\
\text { "And I think [having it done often is] a good thing, because I think each week, or each month, you may be } \\
\text { worse, or you may be better. The first week you can walk about, and then the next month you've fallen, or } \\
\text { something's happened, and you can't do that. So yeah, I think this is very useful." }\end{array}$
\end{tabular}

THEME 3: Tracking health status over time - the relationship to adherence

Higher Level Theme 5: Benefits

\begin{tabular}{l|l} 
7. Comparison & Able to see if there are changes throughout time
\end{tabular}

"It's a great visual, which is probably easier to grasp at once then if we were to compare written format."

"If it could be sent to you on a sort of brag, you're saying two months or something, you could see how you were progressing, if you were getting better or if you were getting worse. You know, that would be excellent if it would be kind of depressing if you get [down] all of a sudden."

"So I would expect to go [up]. And then the next time, to be a little bit more improvement ... That's what I would like my graph to look like. Simple, and my expectation would be, if I come, and I am reasonably compliant, l'd progress. And hopefully, it would shame me, if I didn't progress."

"I also think it's a preventive measurement, if you're getting worse, you have to mindful not to fall."

To understand the treatment process

"[It would] help me understand the process that l've been through."

Higher Level Theme 6: Challenges

8. Data presentation

Cause for confusion

"They've way overcomplicated this, because I think it's very wonderful for the professional reading it - But it's not a terrific thing for ... your regular person."

"I mean, it doesn't make any sense when I just look at it ... Unless [the provider] starts [talking about] what caused that decline."

9. Target Audience

\section{Patient vs Provider vs Research}

"I think this is more for staff, who are taking care of me, if they need to know."

"Maybe that's okay for research ... But it's personally not for me."

"Well, you know it in your head ... You know if you're getting better or if you're slipping ..."

Higher Level Theme 6: Patients' understanding

10. Interpretation of the graphical data

\section{Reasons for incline/decline}

"I like that idea, too, of doing this, if you find yourself improving, then it's great. You just have to remember what you did the last time, the first month. You don't want to say, 'Oh, what did I say last month? Am I feeling better, or not?' So you'd almost have to keep track of what you did, yourself, month by month."

"Well, they would just have to explain the graph at the beginning, like after five months, where are you? And after ten months, where are you? ... And I think that, when I first looked at this, I said, 'What?'”

THEME 4: Comparison of PROM data with peers

Higher Level Theme 7: Relevance of data 
Table 4 (Continued).

II. Relevance to self

\section{Performance of others not relevant}

"Personally, I'm not interested in how l'm measuring up against other people. I'm interested in my own goals, of falling less, or injuring myself less, or having a better quality of life, or whatever... And so, for me, this isn't going to help me comply."

"Not being compared, l'd just like to see that, what you were asking for, is that I want to see a steady increase, if I'm compliant in doing the exercises, I should be improving my strength and flexibility, and balance, all that kind of stuff."

\section{Evidence for benefits from recommendations}

"So, you know, like what difference does it make unless the people who adhered ... Definitely had an $80 \%$ chance of not falling again."

Need to be similar in demographics/conditions

"It would be sometimes comparing apples to oranges, if you're in a group, and maybe l'm a lot better off than the next person that comes in. You're comparing two different physical aspects a lot of times, right? ... Or mental. So it's hard to say."

\section{Higher Level Theme 8: Usefulness of data}

\begin{tabular}{|c|c|}
\hline 12. For patient & $\begin{array}{l}\text { For motivation } \\
\text { "We could get to being ashamed if we didn't do well, it might motivate us to do more." } \\
\text { "If I then got feedback that I was at a different group than what I anticipated ... Then I suppose that would be } \\
\text { a point of discussion or a point of thinking for myself [about needing] to ... become more or less compliant." } \\
\text { For self-awareness } \\
\text { "Well, I would like to know where I'm at ... } \\
\text { because you're not always right. Somebody has to tell you." } \\
\text { Figure out why they are in a certain group } \\
\text { "I probably would change my approach to my recommendations. I would probably ask a bit more questions } \\
\text { when I was there, as to why I was not considered in the moderate, even though I considered I was. But when } \\
\text { I find out that I'm not, I would like to know what it is that I can help myself with." }\end{array}$ \\
\hline 13. For providers & $\begin{array}{l}\text { Find and provide reason for different levels of compliance } \\
\text { "Maybe [it is useful] for the group that's doing the study, or the clinic itself. Maybe it's good for them to know } \\
\text { how you're doing, what group. But for me personally, to find out that l'm in group one, or two, or three, or } \\
\text { four... [does not tell me much]" } \\
\text { "It's maybe more important for the instructor to know this and then use it in consultation with a patient about } \\
\text { trying to find out ... they should have a fairly good idea how the program is working, and if it isn't working, } \\
\text { why isn't it?" }\end{array}$ \\
\hline
\end{tabular}

\section{THEME 5: Patient perspectives on promoting their own adherence}

Higher level theme 9: Performance

14. Direct feedback

Report of/asking how compliant they were

"You know, it'd be really helpful if someone would ask, have I been compliant? No one has ever asked me that. And so I feel guilty because I haven't been completely blind and yet no one asks me like, I guess that's okay."

\section{Higher Level Theme 10: Resources}

\section{Lists}

Recreation/exercise programs

"I think maybe it would be very useful for them not only to let those people know what programs are available under their own auspices, but maybe do a compilation of what other programs may be available in the city or the region. That would be of assistance."

"Getting people on to programs, stops isolation. Isolation is probably a huge [factor] ... It's a huge." "[We] need a training program of fitness instructors who work with seniors." 
Table 4 (Continued).

\begin{tabular}{|c|c|}
\hline 16. Directly from provider & $\begin{array}{l}\text { Ask what patients need } \\
\text { "I think that would be a direct question that could result in this. And if we aren't compliant, why? Do we need } \\
\text { encouragement? Do we need different programs? Why are we not feeling well? And that's questions we can } \\
\text { ask ourselves because I think the whole idea is to improve our quality of life." } \\
\text { "I think l'd feel good if I came in and said, if I even had a list that I checked off for something, but I come in and } \\
\text { have this discussion of how are you doing if you're upset? How are you doing with that? Really helping this one } \\
\text { on one discussion. If I'm saying, 'Oh boy, I get so confused or I'm lazy or whatever,' just to have some } \\
\text { inspiration." }\end{array}$ \\
\hline \multicolumn{2}{|c|}{ Higher Level Theme II: Knowledge } \\
\hline 17. Effect of comorbidities & $\begin{array}{l}\text { How it can hinder compliance } \\
\text { "Well, I think that all these things are interconnected, like you're depressed, because of other stress, that you } \\
\text { cannot follow the recommendations, and all those things. So it's just interrelated to other diseases, and your } \\
\text { health problems. But one thing, leads to another thing." }\end{array}$ \\
\hline 18. Self-reflection & $\begin{array}{l}\text { Prompts to think about reasons they have not been complying } \\
\text { "And if you had a fall, there may be a volunteer could call and say, 'Hey, what's happening? Are you recovering? } \\
\text { Or how did you fall? Can you see any way to stop yourself? Have you learned anything?' Asking those } \\
\text { questions might be an encouragement. I just know l've been here three times, I sometimes would have liked to } \\
\text { have called in and said, 'I want to ask question', but there didn't seem to be resource where I can do that." }\end{array}$ \\
\hline \multicolumn{2}{|c|}{ THEME 6: Potential role for the EQ-5D-5L in promoting adherence } \\
\hline \multicolumn{2}{|c|}{ Higher Level Theme I2: Role in behaviour change } \\
\hline 19. Not having a role & $\begin{array}{l}\text { Already knowing own state of wellbeing } \\
\text { "... in my personal case, I don't think l'd pay much attention to it because I know how I feel. You know inside } \\
\text { how you're feeling." } \\
\text { More important for provider } \\
\text { "Well, if it helps the person that's examining you to understand where you're at, when you come in for your } \\
\text { visit, then I think it's very good." }\end{array}$ \\
\hline $\begin{array}{l}\text { 20. Reasons for its ability to } \\
\text { change behaviour }\end{array}$ & $\begin{array}{l}\text { Improving self-awareness } \\
\text { "I think it improves the awareness ... So you are aware of all the things around you." } \\
\text { "Well, it's important to know how you're doing. That is important. Compared to other people, it's not that } \\
\text { important but to [see] how you are doing, yourself [and] whether it's helping you." } \\
\text { "It will make you a little more self-aware of some of these things ... If you're having more pain, if you're having } \\
\text { less pain, if you're feeling more sad, or more whatever. It just makes you aware, yes." } \\
\text { Positive reinforcement } \\
\text { "Well, and the reason I want to see the long-term answer sheets is, l'm curious to know whether the exercise } \\
\text { program, that l've put myself through, is changing any of these answers, as the year progresses. And so that } \\
\text { seems to me, that, that would give really good feedback to adherence ... " }\end{array}$ \\
\hline
\end{tabular}

[Providers have] to [make recommendations] on the basis ... of what [they've] observed in the tests that are done and also in terms of the individual's approach to what the patient thinks.

\section{Theme 2: EQ-5D-5L Administration and Feedback Timing}

Real-time feedback was a predominant preference, and the importance of it being done at follow-up appointments with the provider present was highlighted. One participant summarized: "I found it more helpful immediately when I was finished, and had an interview with the doctor, and I enjoyed that." Another participant pointed out that feedback should be given when there is enough data to be compared. A selected few suggested that explicitly asking the patient how often they would like to complete the questionnaire and to receive feedback would be preferable, since everyone's conditions are unique. A majority of 
participants also suggested that administration of this questionnaire often would be more helpful, with a frequency of every 1 to 3 months suggested. One participant elaborated: "The reason I suggest that is because I think there may be seasonal aspects to us. You may find you're doing more in the summer." Another reasoned:

... because I think each week, or each month, you may be worse, or you may be better. The first week you can walk about, and then the next month you've fallen, or something [has] happened, and you can't do that. So yeah, I think this is very useful.

There was a divide between participants who would want to complete the questionnaire with an administrator during an appointment, and those who did not mind completing it on their own monthly.

\section{Theme 3: Tracking Health Status Over Time - the Relationship to Adherence}

Focus group participants highlighted three key areas of benefits, challenges and aspects relating to understanding what the trend over time graph represents. The key benefits were to compare pre-post their health to provide motivation to patients and to better understand and appreciate the treatment process. Regarding the chance to visually see their progress over time and with many agreeing, one participant said:

... you could see how you were progressing, if you were getting better or if you were getting worse. You know, that would be excellent if it would be kind of depressing if you get [down] all of a sudden.

Many also agreed if they were able to see improvements over time, it may motivate them to continue to adhere to their prescribed recommendations and to stop behaviors that are stunting improvement or that were making their functioning worse. One participant summarized: “... my expectation would be, if I come, and I am reasonably compliant, I'd progress. And hopefully, it would shame me, if I didn't progress." Two main challenges participants identified for the use of the EQ-5D-5L data over time to impact adherence included data presentation and target audience (e.g., patient versus provider versus researchers). Participants highlighted that how data were presented may be confusing to the target audience, including the number scale used to score the EQ-5D-5L. Depending on who the target audience is, the level of understanding may differ and thus, some participants thought the data were more for the providers or for research. For example, one participant said:

They've way overcomplicated this, because I think it's very wonderful for the professional reading it - but it's not a terrific thing for ... your regular person.

Participants also emphasized that going beyond the PROMs results is important in understanding how useful it is to track health status over time. A participant highlighted: “... they would... just have to explain the graph at the beginning, like after five months, where are you? And after ten months, where are you?" Thus, it would be helpful for patients to understand what clinical factors explain declines or improvements in health status measured by the PROM, as seen by the provider.

\section{Theme 4: Comparison of Patient-Reported Outcome Measure Data with Peers}

Focus group participants had different opinions on the value of comparing PROMs data with their peers in terms of relevance. Some felt that the performance of others is not relevant to their own performance:

Personally, I'm not interested in how I'm measuring up against other people. I'm interested in my own goals, of falling less, or injuring myself less, or having a better quality of life, or whatever ... And so, for me, this isn't going to help me comply.

Some explained that this may in part be due to differences in demographics or other health conditions of others. As one participant pointed out:

It would be sometimes comparing apples to oranges, if you're in a group, and maybe I'm a lot better off than the next person that comes in. You're comparing two different physical [and mental] aspects a lot of times ... So it's hard to say.

Some participants were more concerned with hearing about the evidence: "... what difference does it make unless the people who adhered ... definitely had an $80 \%$ chance of not falling again." Yet, other participants suggested population-level comparative PROMs information may be useful to patients for motivation. In support of population-level comparative PROMs information, one of the participants said: 
If I then got feedback that I was at a different group than what I anticipated ... Then I suppose that would be a point of discussion or a point of thinking for myself [about needing] to ... become more or less compliant.

Another participant commented that it can be useful for patients to have an understanding of their health status relative to their peers. A participant related this to adherence practices:

I probably would change my approach to my recommendations. I would probably ask a bit more questions when I was there, as to why I was not considered in the moderate, even though I considered I was. But when I find out that I'm not, I would like to know what it is that I can help myself with.

One participant also stated that it could be helpful for raising self-awareness: "Well, I would like to know where I'm at ... because you're not always right. Somebody has to tell you." For others, they felt that it may be more useful for providers. Participants suggested that it may assist health-care providers or exercise instructors in understanding reasons for different levels of adherence, which may help them change aspects of the recommendations or programs to promote adherence:

It's maybe more important for the instructor to know this and then use it in consultation with a patient about trying to find out ... they should have a fairly good idea how the program is working, and if it isn't working, why isn't it?

\section{Theme 5: Patient Perspectives on Promoting Their Own Adherence}

Focus groups participants were asked to consider adherence outcomes outside the realm of PROMs to comment on how their own adherence to Falls Prevention Clinic recommendations could be promoted. Three themes emerged: performance, resources and knowledge. Direct feedback on participant adherence was suggested as a performance metric. Lists of recreational or exercise resources, especially those lead by individuals who are experienced in working with seniors, to help further improve their physical functioning was also highlighted as important. A participant stated:

I think maybe it would be very useful for them not only to let those people know what programs are available under their own auspices, but maybe do a compilation of what other programs may be available in the city or the region. That would be of assistance.
One participant elaborated on how programs can help: "Getting people on to programs, stops isolation. Isolation is probably a huge [factor] ... It's a huge." A more direct way of supporting patient adherence was suggested by a participant:

I think that would be a direct question that could result in this. And if we aren't compliant, why? Do we need encouragement? Do we need different programs? Why are we not feeling well? And that's questions we can ask ourselves because I think the whole idea is to improve our quality of life.

Patient knowledge was identified as an important contributor to adherence. Specifically, knowledge of patient's comorbidities and in what ways that may hinder patient adherence was brought up:

Well, I think that all these things are interconnected, like you're depressed, because of other stress, that you cannot follow the recommendations, and all those things. So it's just interrelated to other diseases, and your health problems. But one thing, leads to another thing.

Additionally, patient knowledge acquired through selfreflection was suggested to contribute to adherence. Patient self-reflection may prompt patients to think about their own reasons for non-adherence. As an example, a participant said:

If you had a fall, there may be a volunteer could call and say, 'Hey, what's happening? Are you recovering? Or how did you fall? Can you see any way to stop yourself? Have you learned anything?' Asking those questions might be an encouragement.

\section{Theme 6: Potential Role for the EQ-5D- $5 \mathrm{~L}$ in Promoting Adherence}

Focus group participants reported two contrasting points of view on whether the PROMs questionnaire would be helpful in improving patient's self-awareness. One participant explained:

Well, it's important to know how you're doing. That is important. Compared to other people, it's not that important but to [see] how you are doing, yourself [and] whether it's helping you.

Additionally, one participant highlighted that the graph over time could be used as positive reinforcement:

Well, and the reason I want to see the long-term answer sheets is, I'm curious to know whether the exercise 
program, that I've put myself through, is changing any of these answers, as the year progresses. And so that seems to me, that, that would give really good feedback to adherence ...

One patient participant reported a contrasting viewpoint that the PROMs questionnaire would not play a role in promoting adherence, with some in agreement: “... in my personal case, I don't think I'd pay much attention to it because I know how I feel. You know inside how you're feeling." Few participants added that the questionnaire may be more important for the health-care provider to use when assessing patients, with one stating: "Well, if it helps the person that's examining you to understand where you're at, when you come in for your visit, then I think it's very good."

\section{Discussion}

This patient-oriented qualitative study provides novel insight on the role of PROMs (i.e., EQ-5D-5L) and their potential role in supporting adherence to recommendations received at a Falls Prevention Clinic. This study advances PROMs methodology and content knowledge in two key ways: 1) from a patient-oriented methodology perspective and 2) from a new vulnerable primary care area (i.e., a Falls Prevention Clinic). From a methods perspective, this study included patient partners, who were older adults at high risk of future falls who attended the Falls Prevention Clinic. Patient partners were involved in finalizing the interview prompts and the focus groups. Key findings within the higher-level themes include that patients would find higher frequency of the EQ-5D-5L administration and communication of the feedback useful. The higher frequency may only be useful to promote adherence when other factors are considered. For example, our study highlights the importance of productive provider feedback to facilitate patient understanding and to promote self-awareness, confirming established knowledge of effective patient-physician communication as a significant contributor of patient adherence. ${ }^{52-54}$ Presenting the data that allows patients to see how their health status progressed over time was suggested as helpful and motivating for adherence practices, with the use of comparative data with their peers to a lesser degree. Other findings include the challenges that come with it, the additional resources and knowledge the patients would like to gain in order to help support adherence, and opportunities that the participants identified that come with completing the EQ-5D-5L.

Many of the participants emphasized the role of the health-care provider for almost every prompt, most of which is related to patient-physician communication. For example, in light of the use of the questionnaire results, many indicated that they would be less interested in completing the questionnaire and receiving the results and graphs. Further, they would not find it helpful without the provider's interpretation and explanation of them. This feedback highlights the importance of integration of the provider feedback when implementing PROMs in a primary care setting. This finding is in agreement to that of Dowrick et $\mathrm{al}^{32}$ who reported that both patients and doctors highlighted that a doctor's attentiveness to the patient is crucial in order for routine PROMs collection to be accepted. Participant's suggestions for adherence support require productive patientphysician communication, a significant contributor of patient treatment adherence. ${ }^{52-54}$ Further, participants stated they would value a discussion about why they may be less adherent, why their health status may be declining, or how their comorbidities may be affecting them. Together, these items highlight the importance of patient understanding how measures used to assess their health status relate back to why they may not adhere and how other aspects of their health status also related to their adherence.

Most participants consistently highlighted their preference for frequent EQ-5D-5L administration and feedback. They believe patient experiences are dynamic and should be recorded frequently to capture this. Falls calendars, a gold standard method to prospectively track number of falls, were provided monthly in the Falls Prevention Clinic. Patients suggested the EQ-5D-5L be included monthly alongside falls calendars. A systematic review on the use of PROMs in clinical practice for rheumatoid arthritis $^{33}$ showed the feasibility of doing so, as most studies cited that administration was done every 3 months. Furthermore, the EQ-5D-5L was one of the PROMs that was more frequently collected. Hence, increasing the frequency of EQ-5D-5L administration in the Falls Prevention Clinic should be considered.

Participants generally had positive feedback for the EQ-5D-5L and how it can help support their adherence. Firstly, patients demonstrated a good understanding of the questionnaire itself. They acknowledged that it can be a useful tool for providers to gain a patient's perspective on their conditions and that it can be used to record any trends that the providers can then follow up with them on. 
From these responses, they believe that it can assist in directing the provider's treatment plan for them. These perspectives align and extend findings of another study exploring patients' views on the use of PROMs to assess depression in a clinical setting; patients viewed questionnaires as a tool to enhance objectivity in the practitioner's clinical judgement. ${ }^{32}$ Furthermore, a study that explored the sharing of previous PROMs records revealed that it can help patients understand the effect of treatment, help in medication adherence and help improve trust in the physician. $^{70}$

Notably, some participants highlighted challenges with the presentation of the EQ-5D-5L results graphically. Participants expressed confusion regarding the EQ-5D-5L scores and the way the graphs present the data, as it was difficult for some to interpret. Those who found it confusing were likely to say that the graphs were more useful for the providers themselves and unsuitable for patients. These participants were also likely to deem the graphs as not useful since they know their own state of health. Clear explanations of the graphs do appear to have the potential to mitigate these challenges as some cited the need for explanations from providers, which further emphasizes the importance of patient-physician communication.

An important theme that emerged in our analysis was self-awareness. Most participants believed that completing the questionnaire would help patients become more selfaware of how their conditions are affecting their wellbeing by potentially bringing issues to the patient's attention. It is reported that PROMs can be used for this purpose, thus our current finding further emphasizes the potential it has to increase patient self-awareness. ${ }^{71}$ Through self-awareness, they indicated that it may guide more adherent behaviour, or at least prompt them to reflect on reasons for their results. As well, the participants articulated that the graphs depicting the results over time and comparative adherence levels may also contribute to their self-awareness of how their conditions are affecting them and their level of adherence, respectively. Being able to visualize such results were noted as particularly helpful. Some participants reported motivation to change their behaviors if they observed a decline in their health status or if they see that they belong in a low-adherent category. Indeed, the visualization of personalized PROMs records by showing patients their disease activity course in realtime has demonstrated statistically significant improvements in patients' willingness to remain on treatment and medication adherence. $^{70}$
The incorporation of patient partners who were former patients at the Falls Prevention Clinic was a unique aspect of this study. The main themes that emerged from discussion with the patient partners were benefits to patients, protocol for data presentation, challenges in interpretation of PROMs data and frequency of administration. Patient partners highlighted that much of the potential benefit patients could gain from PROMs are from the personalized graphs showing individuals own PROMs data. Patients were able to see improvements and compare their adherence relative to others, which may motivate them. Patient partners emphasized the large variability in patients' ability to understand the data. As a result, they suggested in agreement with study participants that it would be useful for practitioners to directly ask patients what would be most helpful to improve their adherence. Patient partners added that for those who would find it helpful, more frequent (i.e., monthly) administrations and real-time feedback appeared to be the preference.

This study provides insight on the use of PROMs in a novel, primary care setting among a population at high risk of future fall-related functional decline. A unique aspect to our methodology is the patient-oriented approach that was implemented among a group of older adults at risk of future falls. The patient partners recruited for this study included older adults at high risk of future falls. This study provides a framework for future researchers to consider when working with vulnerable populations such as those at risk of future falls. In collaboration with the patient partners, the focus group questions were refined in a way that provided more clarity to patients. Moreover, the patient partners were present in the focus groups to further simplify anything that was still unclear to participants and later on, we gained their perspectives on what they believed were the important points that the participants brought up, highlighted in Table 1. Next, conducting focus groups as opposed to one-on-one interviews provided the opportunity for discussion between participants and for facilitating the deeper development of ideas. ${ }^{72}$

This study has limitations. As this study was conducted in the urban setting of Vancouver, our findings may not reflect the demographics of rural settings. Because of the diversity of patients seen in the Falls Prevention Clinic, recommendations patients receive vary widely. The responses of participants who received more simple recommendations may not be reflective of patients who require more intense, long-term recommendations of which adherence plays a larger factor in their experience. The number of 
focus groups and participants were small and may affect the generalizability of these findings. Further, the relevance of PROMs to other specific populations such as those who with visual impairment need further research.

\section{Conclusion}

This novel patient-oriented qualitative study among older adults at high risk of future falls highlights several key considerations that are critical to consider for effectively implementing PROMs in this primary care setting. First, participants highlighted the importance of communication with the patient's health-care provider, especially in providing understandable feedback along with other clinical feedback, as a critical factor in supporting patient adherence utilizing the EQ-5D-5L PROM. Participants also emphasized the importance of timely feedback on their health status assessed using the EQ-5D-5L. Additionally, participants suggested that the process of completing the EQ-5D-5L PROM may increase patients' self-awareness through receiving its results and thus may also support patient adherence.

\section{Acknowledgments}

We thank the patient partners and the participants for their time, insights and dedication.

\section{Author Contributions}

All authors made substantial contributions to conception and design, acquisition of data, or analysis and interpretation of data; took part in drafting the article or revising it critically for important intellectual content; agreed to submit to the current journal; gave final approval of the version to be published; and agree to be accountable for all aspects of the work.

\section{Funding}

We acknowledge financial support for this project from the BC SUPPORT Unit Health Economics and Simulation Modelling (HESM) Methods Cluster (Award Number: HESM201), which is part of British Columbia's Academic Health Science Network. The BC SUPPORT Unit receives funding from the Canadian Institutes of Health Research and the Michael Smith Foundation for Health Research. JCD is a Michael Smith Foundation for Health Research Career Scholar. TLA is a Canada Research Chair (Tier 2) in Physical Activity, Mobility, and Cognitive Neuroscience.

\section{Disclosure}

Liu-Ambrose and Davis direct the Falls Prevention Clinic. Bansback directs the Health Economics and Simulation Methods Cluster of the BC Support Unit which is funded by the Canadian Institutes of Health Research. Nick Bansback reports being seconded 0.5 days a week by the BC SUPPORT Unit which funded this project, during the conduct of the study. Jennifer C Davis report grants from Canadian Institutes of Health Research, outside the submitted work. Sponsor's Role: The Canadian Institutes for Health Research had no role in the collection, management, analysis, and interpretation of the data; preparation, review, or approval of the manuscript; and decision to submit the manuscript for publication.

\section{References}

1. Murray C, Lopez A. Global and regional descriptive epidemiology of disability: incidence, prevalence, health expectancies, and years lived with disability. In: Murray C, Lopez A, editors. The Global Burden of Disease. Boston: The Harvard School of Public Health; 1996:201-246.

2. Force USPST, Grossman DC, Curry SJ, Owens DK, et al. Interventions to prevent falls in community-dwelling older adults: US preventive services task force recommendation statement. JAMA. 2018;319(16):1696-1704. doi:10.1001/jama.2018.3097

3. Inouye SK, Studenski S, Tinetti ME, Kuchel GA. Geriatric syndromes: clinical, research, and policy implications of a core geriatric concept. $J \mathrm{Am}$ Geriatr Soc. 2007;55(5):780-791. doi:10.1111/j.1532-5415.2007.01156.x

4. Pluijm S, Smit J, Tromp E, et al. A risk profile for identifying community-dwelling elderly with a high risk of recurrent falling: results of a 3-year prospective study. Osteoporosis Int. 2006;17 (3):417-425. doi:10.1007/s00198-005-0002-0

5. Formiga F, Navarro M, Duaso E, et al. Factors associated with hip fracture-related falls among patients with a history of recurrent falling. Bone. 2008;43(5):941-944. doi:10.1016/j.bone.2008.06.014

6. Rockwood K, Stolee P, McDowell I. Factors associated with institutionalization of older people in Canada: testing a multifactorial definition of frailty. J Am Geriatr Soc. 1996;44(5):578-582. doi:10.1111/ j.1532-5415.1996.tb01446.x

7. SMARTRISK. The Economic Burden of Injury in Canada. Toronto; Ontario; 2009.

8. Palvanen M, Kannus P, Piirtola M, Niemi S, Parkkari J, Jarvinen M. Effectiveness of the chaos falls clinic in preventing falls and injuries of home-dwelling older adults: a randomised controlled trial. Injury. 2014;45(1):265-271. doi:10.1016/j.injury.2013.03.010

9. Chang JT, Morton SC, Rubenstein LZ, et al. Interventions for the prevention of falls in older adults: systematic review and meta-analysis of randomised clinical trials. BMJ. 2004;328 (7441):680. doi:10.1136/bmj.328.7441.680

10. Gillespie LD, Robertson MC, Gillespie WJ, et al. Interventions for preventing falls in older people living in the community. Cochrane Database Syst Rev. 2012;9:CD007146.

11. Close J, Ellis M, Hooper R, Glucksman E, Jackson S, Swift C. Prevention of falls in the elderly trial (PROFET): a randomised controlled trial. Lancet. 1999;353(9147):93-97. doi:10.1016/S01406736(98)06119-4

12. Davis JC, Dian L, Parmar N, et al. Geriatrician-led evidence-based falls prevention clinic: a prospective 12-month feasibility and acceptability cohort study among older adults. BMJ Open. 2018;8(12): e020576. doi:10.1136/bmjopen-2017-020576 
13. Hill KD, Moore KJ, Dorevitch MI, Day LM. Effectiveness of falls clinics: an evaluation of outcomes and client adherence to recommended interventions. J Am Geriatr Soc. 2008;56(4):600-608. doi:10.1111/j.1532-5415.2007.01626.x

14. Sherrington C, Michaleff ZA, Fairhall N, et al. Exercise to prevent falls in older adults: an updated systematic review and meta-analysis. Br J Sports Med. 2017;51(24):1750-1758. doi:10.1136/bjsports-2016-096547

15. Essery R, Geraghty AW, Kirby S, Yardley L. Predictors of adherence to home-based physical therapies: a systematic review. Disabil Rehabil. 2017;39(6):519-534. doi:10.3109/09638288.2016.1153160

16. Findorff MJ, Wyman JF, Gross CR. Predictors of long-term exercise adherence in a community-based sample of older women. $J$ Womens Health. 2009;18(11):1769-1776. doi:10.1089/jwh.2008.1265

17. Picorelli AM, Pereira DS, Felicio DC, et al. Adherence of older women with strength training and aerobic exercise. Clin Interv Aging. 2014;9:323-331. doi:10.2147/CIA.S54644

18. Arkkukangas M, Soderlund A, Eriksson S, Johansson AC. One-year adherence to the otago exercise program with or without motivational interviewing in community-dwelling older adults. J Aging Phys Act. 2018;26(3):390-395. doi:10.1123/japa.2017-0009

19. Black N. Patient reported outcome measures could help transform healthcare. BMJ. 2013;346(jan28 1):f167. doi:10.1136/bmj.f167

20. Davis JC, Liu-Ambrose T, Richardson CG, Bryan S. A comparison of the ICECAP-O with EQ-5D in a falls prevention clinical setting: are they complements or substitutes? Qual Life Res. 2013;22 (5):969-977. doi:10.1007/s11136-012-0225-4

21. Davis JC, Bryan S, McLeod R, Rogers J, Khan K, Liu-Ambrose T. Exploration of the association between quality of life, assessed by the EQ-5D and ICECAP-O, and falls risk, cognitive function and daily function, in older adults with mobility impairments. BMC Geriatr. 2012;12:65. doi:10.1186/1471-2318-12-65

22. Davis JC, Bryan S, Best JR, et al. Mobility predicts change in older adults' health-related quality of life: evidence from a Vancouver falls prevention prospective cohort study. Health Qual Life Outcomes. 2015;13:101. doi:10.1186/s12955-015-0299-0

23. Talib TL, DeChant P, Kean J, et al. A qualitative study of patients' perceptions of the utility of patient-reported outcome measures of symptoms in primary care clinics. Qual Life Res. 2018;27 (12):3157-3166. doi:10.1007/s11136-018-1968-3

24. Turner GM, Litchfield I, Finnikin S, Aiyegbusi OL, Calvert M. General practitioners' views on use of patient reported outcome measures in primary care: a cross-sectional survey and qualitative study. BMC Fam Pract. 2020;21(1):14. doi:10.1186/s12875-019-1077-6

25. Gutacker N, Street A. Use of large-scale HRQoL datasets to generate individualised predictions and inform patients about the likely benefit of surgery. Qual Life Res. 2017;26(9):2497-2505. doi:10.1007/ s11136-017-1599-0

26. Room J, Hannink E, Dawes H, Barker K. What interventions are used to improve exercise adherence in older people and what behavioural techniques are they based on? A systematic review. BMJ Open. 2017;7(12):e019221. doi:10.1136/bmjopen-2017-019221

27. Dolan P, Hallsworth M, Halpern D, King D, Metcalfe R, Vlaev I. Influencing behaviour: the mindspace way. J Econ Psychol. 2012;33 (1):264-277. doi:10.1016/j.joep.2011.10.009

28. Wasson JH, Stukel TA, Weiss JE, Hays RD, Jette AM, Nelson EC. A randomized trial of the use of patient self-assessment data to improve community practices. Eff Clin Pract. 1999;2(1):1-10.

29. Boyce MB, Browne JP, Greenhalgh J. The experiences of professionals with using information from patient-reported outcome measures to improve the quality of healthcare: a systematic review of qualitative research. BMJ Qual Saf. 2014;23(6):508-518. doi:10.1136/bmjqs-2013-002524

30. Von Korff M, Gruman J, Schaefer J, Curry SJ, Wagner EH. Collaborative management of chronic illness. Ann Intern Med. 1997;127(12):1097-1102. doi:10.7326/0003-4819-127-12-1997121 50-00008
31. Reuben DB, Hirsch SH, Frank JC, et al. The Prevention for Elderly Persons (PEP) program: a model of municipal and academic partnership to meet the needs of older persons for preventive services. $J \mathrm{Am}$ Geriatr Soc. 1996;44(11):1394-1398. doi:10.1111/j.1532-5415.1996. tb01416.x

32. Dowrick C, Leydon GM, McBride A, et al. Patients' and doctors' views on depression severity questionnaires incentivised in UK quality and outcomes framework: qualitative study. BMJ. 2009;338:b663. doi: $10.1136 /$ bmj.b663

33. Hiligsmann M, Rademacher S, Kaal KJ, Bansback N, Harrison M. The use of routinely collected patient-reported outcome measures in rheumatoid arthritis. Semin Arthritis Rheum. 2018;48(3):357-366. doi:10.1016/j.semarthrit.2018.03.006

34. Olson RA, Howard F, Lapointe V, et al. Provincial development of a patient-reported outcome initiative to guide patient care, quality improvement, and research. Healthc Manage Forum. 2018;31 (1):13-17. doi:10.1177/0840470417715478

35. Smith PC, Street AD. On the uses of routine patient-reported health outcome data. Health Econ. 2013;22(2):119-131. doi:10.1002/ hec. 2793

36. Trujols J, Portella MJ, Iraurgi I, Campins MJ, Sinol N, de Los Cobos JP. Patient-reported outcome measures: are they patient-generated, patient-centred or patient-valued? J Ment Health. 2013;22(6):555-562. doi:10.3109/09638237.2012.734653

37. Van Der Wees PJ, Nijhuis-van Der Sanden MW, Ayanian JZ, Black N, Westert GP, Schneider EC. Integrating the use of patient-reported outcomes for both clinical practice and performance measurement: views of experts from 3 countries. Milbank Q. 2014;92 (4):754-775. doi:10.1111/1468-0009.12091

38. Osterberg L, Blaschke T. Adherence to medication. $N$ Engl J Med. 2005;353(5):487-497. doi:10.1056/NEJMra050100

39. Horne R, Weinman J. Patients' beliefs about prescribed medicines and their role in adherence to treatment in chronic physical illness. J Psychosom Res. 1999;47(6):555-567. doi:10.1016/S0022-3999(99) 00057-4

40. Horne R, Price D, Cleland J, et al. Can asthma control be improved by understanding the patient's perspective? BMC Pulm Med. 2007;7:8. doi:10.1186/1471-2466-7-8

41. Weinman J, Petrie KJ, Moss-morris R, Horne R. The illness perception questionnaire: a new method for assessing the cognitive representation of illness. Psychol Health. 1996;11(3):431-445. doi:10.1080/08870449608400270

42. Sabaté E. Adherence to Long-Term Therapies: Evidence for Action. Geneva: World Health Organization; 2003.

43. Weinman J. Providing written information for patients: psychological considerations. J R Soc Med. 1990;83(5):303-305. doi:10.1177/ 014107689008300508

44. Horne R. Representations of medication and treatment: advances in theory and measurement. In: Petrie KJ, Weinman JA, editors. Perceptions of Health and Illness: Current Research and Applications. London: Harwood Academic Press; 1997:155-188.

45. Leventhal H, Brissette I, Leventhal E. The common-sense model of self-regulation of health and illness. In: Cameron LD, Leventhal H, editors. The Self-Regulation of Health and Illness Behaviour. New York: Routledge; 2003:42.

46. Kleinman A. Illness meanings and illness behaviour. In: McHugh S, Vallis TM, editors. Illness Behavior: A Multidisciplinary Model. Boston, MA, US: Springer; 1986:149-160.

47. Aikens JE, Nease DE Jr, Nau DP, Klinkman MS, Schwenk TL. Adherence to maintenance-phase antidepressant medication as a function of patient beliefs about medication. Ann Fam Med. 2005;3(1):23-30. doi:10.1370/afm.238

48. Butler JA, Peveler RC, Roderick P, Smith PW, Horne R, Mason JC. Modifiable risk factors for non-adherence to immunosuppressants in renal transplant recipients: a cross-sectional study. Nephrol Dial Transplant. 2004;19(12):3144-3149. doi:10.1093/ndt/gfh505 
49. Charles C, Gafni A, Whelan T. Shared decision-making in the medical encounter: what does it mean? (or it takes at least two to tango). Soc Sci Med. 1997;44(5):681-692. doi:10.1016/S0277-9536(96)00221-3

50. Greenfield S, Kaplan S, Ware JE Jr. Expanding patient involvement in care. Effects on patient outcomes. Ann Intern Med. 1985;102 (4):520-528. doi:10.7326/0003-4819-102-4-520

51. Guadagnoli E, Ward P. Patient participation in decision-making. Soc Sci Med. 1998;47(3):329-339. doi:10.1016/S0277-9536(98)00059-8

52. Lee W, Noh Y, Kang H, Hong SH. The mediatory role of medication adherence in improving patients' medication experience through patientphysician communication among older hypertensive patients. Patient Prefer Adherence. 2017;11:1119-1126. doi:10.2147/PPA.S137263

53. Zolnierek KB, Dimatteo MR. Physician communication and patient adherence to treatment: a meta-analysis. Med Care. 2009;47 (8):826-834. doi:10.1097/MLR.0b013e31819a5acc

54. Ratanawongsa N, Karter AJ, Parker MM, et al. Communication and medication refill adherence: the diabetes study of Northern California. JAMA Intern Med. 2013;173(3):210-218. doi:10.1001/ jamainternmed.2013.1216

55. Brooks C, Ballinger C, Nutbeam D, Adams J. The importance of building trust and tailoring interactions when meeting older adults' health literacy needs. Disabil Rehabil. 2017;39(23):2428-2435. doi:10.1080/09638288.2016.1231849

56. Davis JC, Best JR, Dian L, et al. Are the EQ-5D-3L and the ICECAP-O responsive among older adults with impaired mobility? Evidence from the vancouver falls prevention cohort study. Qual Life Res. 2017;26(3):737-747. doi:10.1007/s11136-016-1487-z

57. Peters M, Crocker H, Jenkinson C, Doll H, Fitzpatrick R. The routine collection of patient-reported outcome measures (PROMs) for long-term conditions in primary care: a cohort survey. BMJ Open. 2014;4(2):e003968. doi:10.1136/bmjopen-2013-003968

58. Kellogg International Work Group. The prevention of falls in later life. A report of the Kellogg International Work Group on the prevention of falls in the elderly. Dan Med Bull. 1987;34(Suppl 4):1-24.

59. Folstein MF, Folstein SE, McHugh PR. "Mini-mental state". A practical method for grading the cognitive state of patients for the clinician. J Psychiatr Res. 1975;12(3):189-198. doi:10.1016/ 0022-3956(75)90026-6

60. Lord S, Sherrington C, Menz H. A physiological profile approach for falls prevention. In: Falls in Older People. Risk Factors and Strategies for Prevention. Cambridge: Cambridge University Press; United Kingdom 2001:221-238.

61. Whitney JC, Lord SR, Close JCT. Streamlining assessment and intervention in a falls clinic using the timed up and go test and physiological profile assessments. Age Ageing. 2005;34(6):567-571. doi:10.1093/ageing/afi178
62. Lawton MP, Brody EM. Assessment of older people: self-maintaining and instrumental activities of daily living. Gerontologist. 1969;9(3 Part 1):179-186. doi:10.1093/geront/ 9.3 Part 1.179

63. Guralnik JM, Ferrucci L, Simonsick EM, Salive ME, Wallace RB. Lower-extremity function in persons over the age of 70 years as a predictor of subsequent disability. $N$ Engl J Med. 1995;332(9):556-562. doi:10.1056/NEJM199503023320 902

64. Yesavage JA, Brink TL, Rose TL, et al. Development and validation of a geriatric depression screening scale: a preliminary report. $J$ Psychiatr Res. 1982;17(1):37-49. doi:10.1016/0022-3956(82) 90033-4

65. van Marwijk HW, Wallace P, de Bock GH, Hermans J, Kaptein AA, Mulder JD. Evaluation of the feasibility, reliability and diagnostic value of shortened versions of the geriatric depression scale. $\mathrm{Br} \mathrm{J} \mathrm{Gen}$ Pract. 1995;45(393):195-199.

66. Spreen O, Strauss E. A Compendium of Neurological Tests. 2nd ed. New York: Oxford University Press, Inc; 1998.

67. Nasreddine ZS, Phillips NA, Bedirian V, et al. The Montreal Cognitive Assessment, MoCA: a brief screening tool for mild cognitive impairment. $J$ Am Geriatr Soc. 2005;53(4):695-699. doi:10.1111/j.1532-5415.2005.53221.x

68. Coenen M, Stamm TA, Stucki G, Cieza A. Individual interviews and focus groups in patients with rheumatoid arthritis: a comparison of two qualitative methods. Qual Life Res. 2012;21(2):359-370. doi:10.1007/s11136-011-9943-2

69. Strauss A, Corbin J. Basics of Qualitative Research: Techniques and Procedures for Developing Grounded Theory. 2nd ed. Thousand Oaks, California: Sage Publications, Inc.; 1998.

70. El Miedany Y, El Gaafary M, Palmer D. Assessment of the utility of visual feedback in the treatment of early rheumatoid arthritis patients: a pilot study. Rheumatol Int. 2012;32(10):3061-3068. doi:10.1007/ s00296-011-2098-1

71. van Cranenburgh OD, Prinsen CA, Sprangers MA, Spuls PI, de Korte J. Health-related quality-of-life assessment in dermatologic practice: relevance and application. Dermatol Clin. 2012;30(2):323332, x. doi:10.1016/j.det.2011.11.004

72. Kitzinger J. The methodology of Focus Groups: the importance of interaction between research participants. Sociol Health Illn. 1994;16(1):103-121. doi:10.1111/1467-9566.ep11347023
Patient Preference and Adherence

\section{Publish your work in this journal}

Patient Preference and Adherence is an international, peer-reviewed, open access journal that focusing on the growing importance of patient preference and adherence throughout the therapeutic continuum. Patient satisfaction, acceptability, quality of life, compliance, persistence and their role in developing new therapeutic modalities and compounds to optimize clinical outcomes for existing disease states are major areas of interest for the journal. This journal has been accepted for indexing on PubMed Central. The manuscript management system is completely online and includes a very quick and fair peer-review system, which is all easy to use. Visit http:// www.dovepress.com/testimonials.php to read real quotes from published authors. 